\title{
Looks Can Cost; Especially On A Small Screen
}

\author{
James Grant ${ }^{1}$, Kathy Lynch ${ }^{2}$, and Julie Fisher ${ }^{3}$ \\ 1. Faculty of IT, Monash University, Victoria, Australia \\ 2. University of the Sunshine Coast, Queensland, Australia, \\ Kathy.Lynch@usc.edu.au \\ 3. Faculty of IT, Monash University, Victoria, Australia. \\ Julie.Fisher@infotech.monash.edu.au
}

\begin{abstract}
Today, the average consumer is comfortable browsing a web site using a desktop, laptop or kiosk computer. However, this is changing a rapid rate as more and more consumers access the same web content using a small screen device such as a mobile phone or personal digital assistant (PDA). Regardless of the consumers' expertise with the mobile device, the experience is becoming frustrating as they try to navigate their way through web content that has been designed for a large screen; a design that results in cumbersome layout, slow-loading images and 'off-screen' navigation points when viewed on a small screen device. The result is dissatisfaction on part of the consumer, and possible loss of revenue for an e-business enterprise. The main objective of this paper is to highlight several techniques and technologies that are currently available that can assist in displaying 'user-friendly' web pages regardless of the screen size of the device.
\end{abstract}

\section{Introduction}

With the growing number of public wireless networks that offer broadband access, and wireless-enabled mobile devices, it is becoming common to access the Web using a mobile device. In exchange for their mobility, small mobile devices lack the common design characteristics of standard desktop computers - such as large screens, millions of colours, full keyboards, and high processing power. Many web applications have been designed to harness the characteristics of these desktop computers, however when presented on a small mobile device they can quite often be difficult or awkward to use, inhibiting the effectiveness and usability of the mobile web environment. Furthermore, these small mobile devices are often expected to perform similar functions and provide a similar functionality to other

Please use the following format when citing this chapter:

Grant, J., Lynch, K., Fisher, J., 2007, in IГIP International Federation for Information Processing, Volume 251, Integration and lnnovation Orient to E-Society Volumel, Wang, W. (Eds), (Boston: Springer), pp. $222-232$. 
computing devices, and in particular, it is expected that these small devices are able to display usable and accessible web content [1].

A small mobile device is used in a unique computing context; the style and length of interaction by the user are somewhat different to a desktop or laptop computer. The mobile device is designed to be used for short and frequent periods of interaction throughout the day or night to allow the user to quickly perform the tasks they want with minimal effort. Consumers become efficient with environments that are familiar to them [2]: the web is no different. When a prospective customer views an e-business web site, the 'view' should be easy to use regardless of the viewing device. However, accomplishing this 'one' view can be both complex and expensive in terms of development, and more importantly, in terms of loss of the mobile ecustomer.

\section{Background}

Nielsen and Morkes [3] state three major features of user behaviour when reading online text; these can bed summarised as:

- users scan the pages, trying to pick out a few sentences or even parts of sentences to get the information they want;

- users prefer text to be short and to the point, and do not like long, scrolling pages;

- users dislike anything that seems like marketing hype preferring factual information.

Of these three features, the first and second are of relevance here, and are critical to designers of effective web sites. We can readily assume that Nielsen and Morkes [3] were referring to online reading of text on normal computer screens, which at the time of the publication were commonly 15 " CRT screens. A study conducted by Jones et al. [4] found that there was a $50 \%$ reduction of user effectiveness when using a web interface on a small screen (screens of today on small mobile devices are commonly smaller today than in 1999- which is when the paper was published), therefore, one could argue that if the study was re-run in 2007, the findings would be similar, or possibly even a higher level of dissatisfaction.

Despite the usability constraints placed on mobile devices, users are currently able to access websites on small screen, web-enabled mobile devices. In an attempt to overcome usability constraints, there are a number of techniques and technologies which re/format the presentation of generalist web information in order to display readable and usable content on a small screen device. The following sections present an overview of these technologies and techniques.

\subsection{Techniques for Manually Coding Multi-format Web Content}

Techniques used to create web content in a number of formats include manually redesigning a site in a specialist mobile programming language, for example, Wireless Mark-up Language (WML), Cascading Style Sheets (CSS) and extended Hypertext Markup Language (XHTML). 


\subsubsection{Wireless Mark-up Language (WML)}

A mobile device displaying a WML page has the ability to organise the web content into a logical structure even though the display area is very limited. WML is a tagbased language that was created for devices that are "hardware-constrained, narrow band [...] with limited input/output capabilities" [5, p.17]. Having a similar structure to HTML, WML is based on the Extensible Markup Language (XML), which is a tag-based markup language that gives the programmer the ability to describe data using their own tags. Due to data transfer limitations there is a need to make file sizes small; WML reduces file size as it allows its developers to specify all text and navigational structure of a site structure whilst automatically catering to the specific needs of portable devices such as small screens, limited processor speeds and slower text input [6, p.66].

Websites coded with WML can be split into a series of sub-pages or 'cards', and placed into collections of similar data or 'decks' [7]. This structure allows the user to quickly navigate through the content without having to wade through design related 'space', such as large graphical navigation bars. Upon launching a WML page, the key elements of the site are downloaded and sorted into decks for the user to explore. Schiller [8] describes each card as containing one unit of user interaction, such as an array of data entry boxes, or a logical group of information, such as a short list of phone numbers [8, p.345].

WML is a simple solution to creating low-bandwidth web content on small screen mobile devices. However, viewing a WML page on a standard desktop computer would be very plain with little interaction when compared to its counterpart desktop HTML version. As such, any organisation wanting to implement a WML version of their e-business services needs to code the 'mobile version' separately from general web content, and therefore duplicating design, development and maintenance processes [9].

\subsubsection{Cascading Style sheets (CSS) and Extendible Hypertext Markup Language (XHTML)}

CSS is a style sheet language used to describe the presentation of a document written in a markup language. CSS has various levels and profiles. Each level of CSS builds upon the last, typically adding new features. Profiles are typically a subset of one or more levels of CSS built for a particular device or user interface. It is within profiles where instructions can be set for various screen sizes [10].

XMHTL has the same depth of expression as HTML, but a stricter syntax; XHTML is the successor to HTML. It was specifically developed for the new devices that are being developed from the standard desktop computer, and is convergence with mobile, telecommunication devices. An XHTML web page can theoretically be faster and made to run more easily on miniaturized devices than comparable HTML web page sizes [11].

\subsection{Technologies for Automatically Coding Multi-format Web content}

In addition to the manual techniques for creating web content for small screen devices, there are commercial products and techniques that enable web pages 
designed for desktop viewing to be viewed reasonably well on a small screen mobile device. One such example is, automatic 'clipping' of visual page content to reduce bandwidth and visual load. There are also a number of commercial products which can be installed on a mobile device, for example Power Browser, which will extract the textual content of a web page and semantically summarise it into an 'information tree' that can be browsed by the user [12]. SmartView is a program that follows a different model of data management; it takes a virtual snapshot of the webpage as if it were to be displayed on a desktop sized screen so the user can 'zoom out' to view the entire page structure and 'zoom in' to read individual pieces of text [13].

\subsubsection{Web clipping}

Palm ${ }^{\mathrm{TM}}$ developed a set of drivers that allows web content to be downloaded in such a way that it is quickly accessible to PDA-like devices. A applications using these drivers are known as 'Web clipping' applications [14]. Web clipping operates on two levels, first, when displaying the page to the user for the first time, the source code is completely scanning and all the 'static data' is extracted. This static data includes graphics, logos, photographs and unnecessary text. These data are stored in the devices cache. On subsequent visits, the static content on the webpage is displayed locally from the device's memory, and only the dynamic content will be updated from the Web [15]. Not only does web clipping conserve the resources of the device by caching data locally, it also increases the speed that a page can be downloaded as less data is required to be transferred to the device.

\subsubsection{Page summation}

Buyukkokten et al [9] found that web content not created using WML and viewed on a small screen has excessive amounts of vertical and horizontal scrolling. Further research conducted by Buyukkokten [12] produced a tool that allows users to access the web content via their mobile device. This tool not only ignores the page's graphical elements, but also its text formatting style, therefore, presents the page's content as a summary of textual information. Being similar to web clipping technology, the entire page's source is scanned for certain content, and is processed by the small screen mobile device before anything is displayed on screen. That is, instead of displaying the traditional format of a web page, only the headings, subheadings, the body text, and link anchors of the pages are displayed.

\subsubsection{Page adaptation}

Chen, Ma and Zhang [13] devised a solution to overcome limited screen size without disrupting the structure of a webpage using a relational 'zooming' method called page adaptation. They developed a piece of software called SmartView that can be installed on a small screen mobile device in order to translate incoming web documents. Through page adaptation techniques, SmartView allows the user to view a miniaturised version of an entire webpage as it would be seen on a desktop computer. The miniaturised version image of the website is divided into visual thumbnails of layout information and data. Each thumbnail contains a section of the webpage, such as a navigation bar, image or textual article. The user is able to select a thumbnail, and zoom in, enabling the content to be readable from the small screen. 
A drawback of this model is that parsing such high amounts of visual information results in high resource use.

\section{The Research}

A study was designed to explore a number of techniques frequently used to display content on small screen mobile devices. Several web sites were selected for viewing by volunteer participants using an $\mathrm{PAA} \mathrm{Q}^{\mathrm{TM}} 4150 \mathrm{PDA}$. The page creation techniques explored where:

- Flat-form (No different to desktop design - HTML) relate to website design that has generally be developed for the desktop user, and therefore assumes that users will be using an average screen size of $1024 \times 768$ pixels.

- Thin-form (CSS/XHTML) may contain an element that reformats a desktop web page to fit into a PDAs limited screen size when the user to specifies they are using a mobile device.

- Wireless Application Protocol-enabled (WAP-enabled) relate to websites written specifically for mobile devices by rewriting the code using Wireless Markup Language (WML) as signified by the use of a .wml file extension.

One goal of the study was to evaluate the design of websites rather than the information management behind the site, therefore, sites that were user driven, contained forums or chat areas, were not considered. Furthermore, pages that required third party software such as web clipping, page summarisation or page adaptation, were not be considered as they require the use of commercial software that is generally not packaged with a PDA or similar device.

\subsection{The Selected Websites}

A range of websites were chosen to allow the exploration between those websites which were designed specifically with mobile devices in mind, and those that did not. Five web sites were selected for the study (see Table 1); all are the types of websites you might expect a typical PDA user might want to access when mobile. Three out of five of the selected sites for the study were sites specifically designed for mobile devices and were available on the web in two formats; desktop and PDA format. The other two sites were chosen for a comparison and selected due to their generally good web design for viewing on a large screen.

Table 4. Websites used in the study.

\begin{tabular}{l|l|l|l}
\hline Site & Business & Archetype & URL \\
\hline National Australia Bank & Bank & Flat form & http://www.national.com.au \\
\hline NineMSN & News & Flat form & http://www.ninemsn.com.au \\
\hline The Age & News & Thin page & http://www.theage.com.au \\
\hline Qantas & Airline & WAP & http://www.qantas.com.au \\
\hline Modern Sci-Fi & Magazine & WAP & http://www.scifi.com \\
\hline
\end{tabular}




\subsection{Participants}

A call for expression of interest in the study was disseminated using the global email system of an organization, and various internal mailing lists. This call returned twenty responses. It was decided that only participants who had reasonable computer skills and were web 'savvy' would participate in the study, therefore, a short survey collected selection criteria data, of which 17 of the 20 potential participants qualified.

Prior to conducting the study, additional participant data was collected. This included PDA ownership (8 participants: $47 \%$ ), type of PDA owned ( $88 \%$ owned a Hewlett Packard ${ }^{\mathrm{TM}}, 12 \%$ owned a Palm ${ }^{\mathrm{TM}}$ ). The participants who owned a PDA were also asked what they used it for: their usage was as follows:

$25 \%$ for diary/calendar

$24 \%$ for note-taking

$17 \%$ for surfing the web

$17 \%$ for games

$17 \%$ for storing/transferring files

\subsection{Questionnaire}

The primary data gathering tool of the study was a nine question Likert-type questionnaire (see Table 2). The users were asked to place a mark on a scale for each statement, ranging from "strongly agree" (5) to "strongly disagree" (1), or "not applicable" (null) if they believed the question was not relevant. The questions were based on Shneiderman's Golden rules for interface design [16 pp 74-75], and Nielson and Molick's Usability Heuristics [13]. The quantitative questions were followed with two general qualitative questions. The same questionnaire was used to evaluate each of the three websites.

Table 2: Questions, Q1-9 used a Likert-type scale, Q10-11, were open-ended Question:

1 Upon using it, I quickly understood the purpose and motive of this site."

2 I was easily able to return "home" if I needed to

3 The visual design of the site was consistent

4 The site is intuitive and I did not require instructions on how to use it

5 The clarity of the text was clear and easy to read."

6 The sites navigational tools were apparent and easy for me to use

7 I felt that color added value, or would add extra value to the site."

8 The textual information was categorised in a logical order."

9 I consider this site to be easy to use."

10 Was there any part of the interface that encumbered your use of the site?

11 Optional comments: 


\section{Results and findings}

Descriptive tests of mean score and standard deviation (Table 3) were calculated on the data to highlight the participants' perceptions of recognised design features of the site.

Table 3: Interface usability: Mean and Standard Deviation

\begin{tabular}{|c|c|c|c|c|c|c|}
\hline & & $\begin{array}{c}\text { National } \\
\text { Flat } \\
\text { form }\end{array}$ & $\begin{array}{c}\text { NineMSN } \\
\text { Flat } \\
\text { Form } \\
\end{array}$ & $\begin{array}{c}\text { The Age } \\
\text { Thin- } \\
\text { page }\end{array}$ & $\begin{array}{l}\text { Qantas } \\
\text { WAP } \\
\end{array}$ & $\begin{array}{l}\text { Sci-Fi } \\
\text { WAP } \\
\end{array}$ \\
\hline \multirow[t]{2}{*}{ 1. Clearly defined purpose } & $\mathrm{m}$ & 3.35 & 3.41 & 4.59 & 4.35 & 4.12 \\
\hline & sd & 0.86 & 1.00 & 0.51 & 0.70 & 1.22 \\
\hline \multirow[t]{2}{*}{ 2. Ability to return 'home' } & $\mathrm{m}$ & 2.24 & 2.76 & 3.29 & 4.59 & 3.24 \\
\hline & sd & 1.03 & 1.15 & 1.49 & 0.80 & 1.30 \\
\hline \multirow[t]{2}{*}{ 3. Consistent visual design } & $\mathrm{m}$ & 3.35 & 2.53 & 4.47 & 4.24 & 4.12 \\
\hline & sd & 1.12 & 1.18 & 0.52 & 0.56 & 0.99 \\
\hline \multirow[t]{2}{*}{ 4. Intuitive design } & $\mathrm{m}$ & 2.71 & 3.29 & 4.53 & 4.12 & 3.76 \\
\hline & sd & 1.05 & 0.92 & 0.62 & 0.49 & 1.09 \\
\hline \multirow[t]{2}{*}{ 5. High clarity of text } & $\mathrm{m}$ & 2.18 & 3.06 & 4.47 & 4.18 & 4.29 \\
\hline & sd & 0.81 & 1.14 & 0.62 & 0.39 & 0.99 \\
\hline \multirow[t]{2}{*}{ 6. Apparent navigational tools } & $\mathrm{m}$ & 1.88 & 2.41 & 3.82 & 3.76 & 3.12 \\
\hline & sd & 0.86 & 1.00 & 1.07 & 1.25 & 1.45 \\
\hline \multirow[t]{2}{*}{ 7. Colour used for value } & $\mathrm{m}$ & 2.71 & 3.06 & 3.59 & 3.18 & 3.06 \\
\hline & sd & 1.16 & 1.03 & 1.23 & 1.13 & 1.03 \\
\hline \multirow[t]{2}{*}{ 8. Logical organisation } & $\mathrm{m}$ & 2.65 & 2.94 & 4.35 & 4.06 & 3.88 \\
\hline & sd & 1.06 & 0.90 & 0.61 & 0.83 & 0.93 \\
\hline \multirow[t]{2}{*}{ 9. User Satisfaction } & $\mathrm{m}$ & 1.59 & 2.12 & 4.47 & 4.24 & 3.65 \\
\hline & sd & 0.62 & 0.70 & 0.62 & 0.75 & 1.32 \\
\hline
\end{tabular}

1. Clearly defined purpose and motive: For each website used in the study, the majority of participants "strongly agreed", or "agreed" that they understood the purpose and motive of the given website. The users believed that The Age website (thin page archetype), had the most clear purpose and motive. All participants either "agreed" or "strongly agreed" that The Age was the quickest to be understood, whereas the users believed that NineMSN had a purpose that was much slower to be understood with $47 \%$ of the users responded with "unsure" or "disagreeing" that they quickly understood it. The majority of users "agreed" with each other about a website's ability to be quickly understood. However, the Sci-fi website had the most dispersed results, with $53 \%$ of the users "strongly agreeing" and $24 \%$ of the users "disagreed" or "strongly disagreed".

2. Ability to return 'home': Mobile devices generally do not allow multiple browser windows, so the user must follow a single path of navigation; therefore it is important that the user is able to return to the interface's 'home' without having to 
restart the browser. The Qantas website (WAP-enabled archetype) provided a home link on each page back to the main menu: $71 \%$ of users "strongly agreed" and $23 \%$ "agreed" that they were easily able to return 'home' when using the Qantas website, only $6 \%$ disagreed. In comparison, The National Bank website (Flat-form archetype) provided a home link on the desktop version of the website, but as it does not translate well to browsing using a PDA, making it difficult to return to the main index of the website, with $77 \%$ of users "disagreed" or "strongly disagreed" that they were able to return 'home' if they needed to.

3. Consistent visual design: Over $85 \%$ of users for each Qantas, National Bank and Sci-fi websites "agreed" that they contained a consistent visual design. When reviewing The Age web site, $47 \%$ of the users "strongly agreed" and $53 \%$ "agreed" that the visual design of The Age website was consistent. NineMSN website (flat form archetype) was the lowest scoring site with $59 \%$ of participant responses claiming that the design was inconsistent.

4. Intuitive design: PDAs have a limited number of possible user interactions, so the interface should be designed to minimise incorrect user actions. The Age and Qantas websites had the majority of positive user responses. In addition, The Age had the highest percentage $(59 \%)$ of users stating that the website contained an intuitive design. The National Bank website had the highest number of users (71\%) stating that the web site did not have an intuitive design.

5. High clarity of text: The Age, Qantas and the Sci-fi websites had the majority of users stating that the text on the site was easy to read. In contrast however, $71 \%$ of the users thought that the text on the National Bank website was difficult to read.

6. Navigational tools: The Age, Qantas and the Sci-fi websites had similar results in that $65 \%$ or greater of responses stated that the site's navigation tools were apparent and easy to use. The two flat form archetype sites (National Bank and NineMSN) scored poorly, each having $75 \%$ users "disagreeing" or "strongly disagreeing" that the website's navigational tools were apparent and easy to use, with the National Bank website rating the worst.

7. Value of colour: The Age website scored highly, with $65 \%$ of users agreeing or strongly agreeing that colour added value to the website. The response for the Qantas and NineMSN websites was significantly lower, with each site having 35\% of users stating that colour did not add extra value to the website. The National Bank website scored the lowest with $41 \%$ stating that the use of colour did not add value to the site.

8. Logical organisation of content: The Age website scored the highest in this question with $94 \%$ of the users "agreeing" or "strongly agreeing" that its content was logically structured. The Qantas and Sci-fi websites each scored highly with both having over $76 \%$ of the users "agreeing" or "strongly agreeing" that the textual information was categorised in a logical order. This was followed by NineMSN then the National Bank.

9. User Satisfaction: When taking into consideration the previous results, predictably The Age website was perceived as the most easy to use with $94 \%$ of the users agreeing or strongly agreeing that it was easy to use. This was closely followed by the Qantas website, then the Sci-fi website. The NineMSN website was perceived as not easy to use (82\%). The National Bank website was the least easy to use with 
no participant stating that it was easy to use, $6 \%$ stating that they were unsure, and an overwhelming $94 \%$ stating that is was not easy to use.

According to the aggregate of the responses from the participants, The Age (Thin page archetype) was the most 'usable' website due to its consistently high mean score across all categories. On the other hand, both NineMSN and the National Bank (Flat form archetypes) generally scored low across all categories. Qantas and Sci-fi (WAP-enabled archetypes) were generally middle-ranked (see Table 4).

Table 4: Usability of the selected sites (and corresponding archetype

\begin{tabular}{|c|c|}
\hline \multirow[b]{2}{*}{ Most usable } & Website \\
\hline & $\begin{array}{l}\text { The Age } \\
\text { (Thin page) }\end{array}$ \\
\hline \multirow[b]{4}{*}{ Least usable } & $\begin{array}{l}\text { Qantas } \\
\text { (WAP-enabled) }\end{array}$ \\
\hline & $\begin{array}{l}\text { Sci-fi } \\
\text { (WAP-enabled) }\end{array}$ \\
\hline & $\begin{array}{l}\text { NineMSN } \\
\text { (Flat form) }\end{array}$ \\
\hline & $\begin{array}{l}\text { National Bank } \\
\text { (Flat form) }\end{array}$ \\
\hline
\end{tabular}

\section{Conclusion}

A key goal when designing web sites for mobile devices, and in particular for ebusiness, is to allow the user to be able to access information quickly and easily. Effective interfaces should give a sense of control, be apparent to the user, and allow the user to "quickly see the breadth of their options, grasp how to achieve their goals, and do their work" [17].

Kim and Albers [18] believe that many web design guidelines will often consider a PDA as a portable computer, and the screen to simply be a "miniature computer monitor" [18, p.194]. This outlook can be somewhat problematic when attempting to effectively display text on a mobile device that has limited input and display space when compared to a desktop computer. While users may inherently adopt similar text browsing habits on a PDA as they do for a desktop view, however, additional 'rules' should be applied to a PDA due to the vast physical differences between display a document on a desktop to that of displaying on a small screen device.

The study presented details the views of typical PDA users relating to their preference in relation to a website's presentation on a PDA. The results of the study show that users prefer simplistic interfaces that require minimal interaction, such as those presented in flat form and WAP-enabled website archetypes. The comments given by the users suggest that they prefer websites which follow the standard form of a website with vertical scrolling rather than the 'deck and card' style of WAPenabled pages. While WAP-enabled sites are designed specifically for mobile 
devices, thin page sites more closely mirror the interfaces we commonly associate with on a desktop computer screen.

However, the use of a web-formatting technology to display the same sourced content appealing on any device does not guarantee that the website is 'user-friendly'. Careful designing of the site, regardless of the display device, must be taken seriously.

"Usability rules the web. Simply stated, if the customer can't find a product, then he or she will not buy it" $[19, \mathrm{p} .10]$.

(Note: The National Bank, Australia, have since addressed the problems with viewing their website on small screen mobile devices, therefore, if the study was conducted today, the results for the National Bank would be more positive.)

\section{References}

1. Preece, J., Y. Rogers and H. Sharp (2002). Interaction Design -- beyond human computer interaction. USA, John Wiley and Sons.

2. Cooper, A. (1995). About Face - The essentials of user interface design. IDG Books Worldwide, California, USA.

3. Nielsen, J, and Morkes (1997). Concise, scannable and objective: How to write for the Web. Accessed on April 2003, from http:/www. useit.com/papers/webwriting/writing.html

4. Jones, M, Marsden, G, Mohd-Nasir, N, Boone, K, and Buchanan, G. (1999). Improving Web interaction on small displays. In Proceedings of the Eighth International World Wide Web Conference (pp. 1129-1137). Toronto.

5. Mann, S. (2000). Programming Applications with the Wireless Application Protocol: The complete developer's guide. USA, John Wiley \& Sons, Inc.

6. Bulbrook, D. (2001). WAP: A beginner's guide. Berkley, California, Osbourne

7. Buchanan, G, Jones, M, Thimbleby, H, Marsden, G, and Pazzani, M. (2001). Improving mobile Internet usability. In Proceedings of the Tenth International Conference on World Wide Web (pp. 673-680). Hong Kong: International conference on World Wide Web.

8. Schiller, J. (2000). Mobile Communications. Harlow, UK, Addison-Wesley.

9. Buyukkokten, O, Kaljuvee, O, Garcia-Molina, H, Paepcke, A, and Winograd, T. (2002) Efficient web browsing on handheld devices using page and form summarization. ACM Transactions on Information Systems. 20 (1), 82-115.

10. Wikipedia (2007a) http://en.wikipedia.org/wiki/Css Accessed April 2007

11. Wikipedia (2007b) http://en.wikipedia.org/wiki/XHTML Accessed April 2007

12. Buyukkokten, O. (2004). Power Browser. Accessed on November 2004 from http://www-diglib.stanford.edu/ testbed/doc2/PowerBrowsing/

13. Chen, Y, Ma, W. Y. and Zhang, HJ. (2003). Detecting Web Page Structure for Adaptive Viewing on Small Form Factor Devices. In Proceedings of the twelfth international conference on World Wide Web (pp.225-233). Hungary: WWW 2003.

14. Palm. (2000). Wireless Enterprise Applications for Mobile Information Management. Accessed on April, 2003, from http:/www.palmos.com/dev/tech/webclipping/wireless.pdf

15. Freire, J, Kumar, B, and Lieuwen, D. (2001). WebViews: accessing personalized web content and services. In Proceedings of the International World Wide Web Conference (pp. 576-586). Hong Kong: International World Wide Web Conference. 
16. Shneiderman, B. (1998). Designing the User Interface. Addison-Wesley, USA.

17. Togazzini, B. (2003). First Principles. Accessed on September 2003 from http://www.asktog.com/basics/firstPrinciples.html

18. Kim, L, and Albers, M. (2001). Web Design Issues when Searching for Information in a Small Screen Display. In Proceedings of the 19th annual international conference on Computer documentation (pp. 193-200). Mexico.

19. Nielsen, J. (2000). Designing Web Usability. USA, New Riders Publishing. 